\title{
A TEORIA DA LINGUAGEM DE DEWEY E O CONTEXTO CULTURAL DA INVESTIGAÇÃO HUMANA
}

\author{
Caio Cesár Cabral \\ Universidade de São Paulo - USP \\ caiock@gmail.com
}

Resumo: Neste artigo discutimos como se produz, mais uma vez no contexto da teoria da investigação de Dewey, a transformação das interações puramente orgânicas entre homem e ambiente em interações inteligentes, vale dizer, em pesquisa humana capaz de solucionar problemas. Exporemos, mais precisamente, as bases culturais da teoria da investigação do filósofo, acompanhando passo a passo a análise que ele faz da linguagem e dos símbolos linguísticos.

Palavras-Chave: Teoria da investigação. Cultura. Teoria da linguagem. John Dewey.

\section{DEWEY'S THEORY OF LANGUAGE AND THE CULTURAL CONTEXT OF HUMAN RESEARCH}

Abstract: In this paper we discuss how is produced, in the context of Dewey's theory of inquiry, the transformation of purely organic interactions between man and environment into intelligent interactions, that is, into human research capable of solving problems. We shall, more precisely, examine the cultural bases of the philosopher's theory of inquiry, following step by step his analysis of language and linguistic symbols.

Keywords: Theory of inquiry. Culture. Theory of language. John Dewey.

\section{Introdução}

Continuando a tomar como norte de nosso estudo a obra Lógica: Teoria da Investigação (1938), vemos que são dois os antecedentes importantes da teoria da investigação de Dewey. Um deles é o behaviorismo: já vimos, em artigos que publicamos antes, a enorme importância que tem, para a concepção de experiência de Dewey, o esquema "estímulo-resposta" fornecido por fatos observáveis na experiência animal (humana ou não). Dewey, com efeito, além de admitir abertamente a influência do comportamentalismo em sua filosofia, destaca ainda qual é, segundo lhe parece, o ponto de partida desta corrente psicológica: 
Sucintamente, o ponto de partida dessa teoria é a concepção de que o cérebro é um órgão de coordenação de estímulos sensoriais (aos quais pode-se adicionar modificações causadas pelos hábitos, por memórias inconscientes, ou pelo que é hoje chamado de 'reflexos condicionados'), com o propósito de efetivar respostas motoras adequadas (Dewey, 2007, p. 237).

Assim, garante o filósofo que a ação de todas as espécies animais, e mesmo a do homem, se dá sempre como resposta a estímulos externos: "as galinhas, por hábito, por reflexo condicionado, correm em direção ao fazendeiro quando este imita o cacarejo, ou quando ouvem o barulho do milho na gamela" (Dewey, 1958, p. 177). O outro antecedente do pensamento de Dewey é a teoria da evolução orgânica. Ora, para o filósofo, aquilo que, nos organismos inferiores, se chama "adaptação", no homem não só tem um aspecto teleológico, como ainda origina o pensamento. Veremos, então, a partir de agora, como surge exatamente, a partir do comportamento biológico adaptativo, a reflexão enquanto resposta ao ambiente.

Julgamos importantes as considerações acima por nos ajudarem a começar a compreender o modo pelo qual Dewey concebe a passagem da conduta biológica para a conduta intelectual. Somos conduzidos, assim, em nosso estudo do naturalismo de Dewey, às bases culturais de sua teoria da investigação.

\section{O contexto cultural da investigação}

Já sabemos da ênfase que Dewey dá ao fato de que o organismo forma parte do mundo natural, estando com ele em constante interação. Quando, graças ao desenvolvimento da linguagem e dos símbolos, essas interações são dirigidas a consequências previstas, elas adquirem então a qualidade de interações inteligentes, o que abre caminho para o surgimento da pesquisa humana capaz de solucionar problemas. Diríamos que a expressão "consequências previstas" significa, neste contexto, um acontecimento mentalmente antecipado, ou um raciocínio no qual supomos que a execução de determinado ato certamente produzirá resultados concretos esperados. Na Lógica, e também em Experiência e Natureza (1925), Dewey concebe a linguagem humana como interação natural, já que ela se mostra também como um meio eficaz de adaptação. Explica o autor:

Os gestos e os gritos não são, em primeiro lugar, expressivos e comunicativos. São modos de comportamento orgânico, tanto quanto a locomoção, o agarrar e o triturar. A linguagem, os signos e a significação vêm à existência não por intenção e por desejo, e sim por excesso, como subprodutos, nos gestos e no som. A história da linguagem é a história do uso feito dessas ocorrências; um uso que é eventual tanto quanto memorável (Dewey, 1958, p. 175).

$\mathrm{Na}$ visão do filósofo, portanto, a ocorrência de ideias que podem ser traduzidas em palavras se dá ligada de forma contínua às ocorrências físicas. Com a comunicação, os objetos naturais, 
adquirindo significado, adquirem, por intermédio deste, representantes, substitutos, signos e implicações, os quais se apresentam como infinitamente mais dóceis para o manejo, mais permanentes e mais aptos quanto à acomodação, relativamente aos eventos em seu estado anterior (Dewey, 1958, p. 167).

Os elementos qualitativos imediatamente presentes não mais implicam submissão ao meio. Tais imediatidades tornam-se sujeitas à "inspeção, contemplação e elaboração ideal ou lógica; quando alguma coisa pode ser dita das qualidades, estas são provedoras de instrução. Aprender e ensinar vêm à existência, e não há evento que não possa fornecer informação" (Dewey, 1958, p. 167).

Para Dewey, portanto, o meio em que os seres humanos vivem, atuam e investigam não é puramente biológico, mas é também cultural. Das relações entre os seres humanos surgem problemas que induzem a investigar, e os órgãos para enfrentar estes problemas não são só os olhos e os ouvidos, mas também sentidos e significados, que se desenvolvem no curso do viver, junto com os modos de formar e transmitir a cultura e todos os seus componentes. Assim, o modo pelo qual os seres humanos respondem às condições físicas "é influenciado por seu ambiente cultural" (Dewey, 1960, p. 42). Fogo e som, exemplifica Dewey, são fatos físicos, mas são raras as vezes em que os seres humanos respondem a tais fatos de modo puramente físico. Estas reações só se dão quando, por exemplo, simplesmente corremos das chamas de um incêndio, para que não haja risco de nos queimarmos, ou quando nos assustamos com um ruído. Tais modos de comportamento se dão, mais precisamente, no plano puramente biológico, embora não sejam estes, ressalta Dewey, "os casos típicos da conduta humana" (Dewey, 1960, p. 42). Os fatores que propriamente distinguem as atividades humanas são coisas como o uso do fogo para a preparação de alimentos ou o uso do som para falar ou explicar algo a alguém. Portanto, Dewey vê na conduta humana uma forte interligação entre os meios físico e cultural, a tal ponto que nossas interações com o ambiente se acham profundamente afetadas por esta interligação.

\section{A cultura e a linguagem}

Antes de prosseguirmos na discussão dos fundamentos culturais da teoria da investigação de Dewey, precisamos deixar estabelecido o modo como o filósofo concebe a cultura. Nosso autor não perde de vista que a cultura diz respeito a todos os aspectos de uma realidade social: a organização da vida de uma comunidade, as condições materiais desta vida, as formas de se entender e interpretar a realidade, etc. Cultura, neste contexto, é o conhecimento que uma sociedade tem a respeito de si mesma e de outras sociedades, e inclui ainda as maneiras como esse conhecimento é expresso por essa sociedade, como no caso de sua arte, sua religião, sua tecnologia e sua política. Entram em cena, então, os processos de simbolização, ou seja, processos de substituição de um objeto qualquer por aquilo que o representa. Isso permite que uma ideia expresse um acontecimento, um sentimento, etc. A simbolização, e portanto a linguagem, permitem ainda que 0 conhecimento seja condensado, e que a experiência acumulada seja transmitida e transformada. Defende Dewey que a própria lógica "é a consequência das interações sociais, do convívio, da assistência mútua, da direção e ação organizada 
na guerra, nas festividades, no trabalho" (Dewey, 1958, p. 171). Dewey, portanto, ao desenvolver sua teoria da investigação humana, vê na linguagem o fator cultural mais importante. Com efeito, é a partir do uso dos símbolos, com seus respectivos sentidos, que se pode planejar e organizar uma ação coletiva de amplo alcance e de efeitos duradouros para toda uma comunidade.

É preciso que observemos também que, para Dewey, nem todos os fatores da vida social e cultural acham-se já presentes nos processos puramente orgânicos. O homem, sendo um animal social, aprende a resolver situações vivenciadas com o auxílio de certos meios "que não têm precedentes no nível biológico orgânico" (Dewey, 1960, p. 43). O homem não é sociável do mesmo modo como o são as abelhas, por exemplo, pois as ações do primeiro carregam a marca do ambiente em que vive, a qual é transmitida culturalmente. $\mathrm{O}$ que o homem faz e o modo como 0 faz não está determinado unicamente pela estrutura orgânica; também o determina a influência da herança cultural, incorporada nas tradições, instituições, costumes e crenças. Mas por que - podemos perguntar - Dewey reintroduz fatos como estes, já tão familiares aos filósofos? Neste ponto, pensamos ser necessário tentar aprofundar o sentido da relação que Dewey vê entre natureza e cultura. Para ele, embora a conduta biológica antecipe (no sentido de preparar o caminho para) a conduta racional, ela não contém em si mesma algumas particularidades que surgem de fato apenas no contexto da cultura humana, tais como a linguagem e o pensamento lógico. E, embora esta seja uma diferença importante entre a conduta racional e a conduta puramente vital e física, ela não é suficiente para se fazer pensar que biologia e cultura sejam elementos essencialmente antitéticos. Afinal, muito do que é realizado, mesmo na esfera de uma cultura transmitida, é realizado, em última instância, enquanto um modo de os homens ajustarem-se às condições naturais do mundo em que vivem. Se tomarmos como exemplo as técnicas de caça de determinada comunidade, encontraremos que a invenção, o ensinamento e o aperfeiçoamento destas técnicas podem ser entendidos como sendo nada mais que um modo rápido e eficiente de os integrantes da comunidade obterem do meio 0 alimento de que necessitam. E há outras criações humanas, como a pesca e a agricultura, todas elas, enfim, realizadas a partir do momento em que o homem deixa de simplesmente contentar-se com o que lhe é imediatamente dado no exterior. Através da criação e da invenção, o homem não apenas adapta-se como transforma a natureza. Assim, pensamos ser correto afirmar que, para Dewey, os campos orgânico e cultural da conduta têm entre si uma relação de continuidade.

$\mathrm{Na}$ Lógica, o filósofo salienta que mesmo as estruturas físicas dos indivíduos resultam modificadas pela "influência que o ambiente cultural exerce sobre suas atividades" (Dewey, 1960, p. 43). Sobretudo o fenômeno da aquisição da linguagem é o que explica a incorporação das condições culturais à estrutura física dos humanos. Os atos de falar, ler ou mesmo exercer qualquer arte são os melhores exemplos de transformações orgânicas ocasionadas pelo meio cultural: "Esta modificação do comportamento orgânico no e pelo ambiente cultural explica, ou melhor, representa a transformação da conduta puramente orgânica em conduta dotada de propriedades intelectuais" (Dewey, 1960, p. 43). O ato investigativo e as operações intelectuais acham-se, pois, antecipados pela conduta de tipo biológico. Mas Dewey toma o cuidado de chamar a atenção, ao tratar das bases naturalistas de sua teoria da pesquisa, para a questão das diferenças significativas existentes entre as atividades humanas e as de outras formas biológicas. A preocupação do filósofo neste ponto é advertir especialmente contra as suposições segundo as quais 
a diferença diz respeito a propriedades humanas advindas de fontes não naturais. $A$ tese que ele sustenta é a de que esta diferenciação está ligada ao desenvolvimento da linguagem, a qual se dá com base em ações biológicas prévias e em conexão com amplas forças culturais. Não se trata de acompanhar ou explicar como se dá o "salto" do comportamento orgânico a algo radicalmente distinto dele, como, por exemplo, a capacidade de uma pura intuição a priori. A transformação da conduta em questão é vista por Dewey como sendo, antes, um processo contínuo em que se desenvolvem gradualmente novos modos de atividade natural.

Outro fato importante é trazido por Dewey com a afirmação de que "o comportamento orgânico se acha centrado em organismos particulares. Esta afirmação se aplica ao inferir e ao raciocinar, como a outras tantas atividades existenciais" (Dewey, 1960, p. 44). Explicaríamos tal fato começando por lembrar que cada organismo humano possui a capacidade de, partindo de alguns passos inferenciais, chegar a certas conclusões. Mas para que estas conclusões sejam compartilhadas e consideradas válidas por outros humanos, o objeto investigado, assim como quaisquer operações racionais a ele relacionadas, têm que assumir caracteres que possam ser compreendidos por todos os outros seres capazes de raciocinar e tirar conclusões. O que significa que a constituição especial do organismo individual, tão importante no comportamento biológico, deve ser "subjugada", segundo Dewey (Dewey, 1960, p. 44). Deve ser, diríamos nós, submetida a certas exigências coletivas no que respeita ao procedimento intelectual e à investigação controlada.

Dewey também considera grande a influência que têm, na construção dos juízos humanos, "as emoções e os desejos" (Dewey, 1960, p. 44). De fato, no nível dos fatores orgânicos, o indivíduo, com suas peculiaridades congênitas ou adquiridas, participa muito ativamente na produção de ideias e crenças. Mas, uma vez mais, estas só podem ser aceitas por todos e ser consideradas de fato fundamentadas quando se exclui o efeito de tais peculiaridades. Basta trazermos, para ilustrar este ponto, o caso de uma teoria, ou solução de um problema, que pode ter sua confiabilidade gravemente comprometida pela impaciência do pesquisador ou por um forte desejo seu de apresentar uma resposta rápida à dificuldade. Tem forte peso, portanto, na objetividade intelectual, a eliminação de fatores pessoais nas operações com as quais alcançamos conclusões objetivas.

\section{A conduta, as proposições lógicas e as características da linguagem}

Dentre os aspectos pertinentes a esta transformação da conduta humana, notamos, sobretudo na Lógica, o de que, a princípio, "o comportamento orgânico é assunto estritamente temporal" (Dewey, 1960, p. 45). Para tentar deixar claro o que Dewey quer aqui dizer, consideremos a situação de alguém que segue viagem pelo deserto e vê, num certo instante, pegadas humanas na areia. Depois avista, ao longe, o que parece ser um homem; pára, então, por algum tempo, hesitando, com medo de que o homem em questão represente perigo, e termina por abandonar, enfim, seu rumo inicial, tomando outra direção. Estes são, pois, estados e atos orgânicos que se sucedem no tempo à medida que surgem situações ambientais diferentes. Mas quando a conduta humana se formula intelectualmente, mesmo estando relacionada às condições ambientais, então "temos como resultado proposições, e os termos de uma proposição não guardam entre si relações temporais" (Dewey, 1960, p. 45). Aqui, Dewey se refere a relações puramente 
lógicas, como a que existe entre o sentido de uma proposição e o que disto se pode inferir. A coerência de operações deste tipo não depende de que esteja ocorrendo no meio natural uma sucessão qualquer de eventos. Neste momento, no entanto, pode-se perguntar como exatamente se dá, para Dewey, a passagem de afirmações cujo conteúdo é de caráter temporal para as proposições lógicas utilizadas na investigação humana controlada. Encontramos na obra do autor inúmeras explicações a respeito de transformações desta natureza: em uma delas, temos a transformação de natureza lógica que ocorre em uma proposição rigorosamente empírica ou temporal do tipo "Todos os casos até agora observados são tais e tais" (Dewey, 1960, p. 194). Explica, então, Dewey que "quando se tem determinado com exclusividade [...] as condições nas quais os fenômenos são assim ou assado, é possível enunciar uma proposição universal em forma de lei: Sempre que as condições sejam estas, as consequências serão estas outras" (Dewey, 1960, p. 195).

O que se tem, portanto, é a inferência enquanto operação lógica que permite a abstração das condições temporais. Em outro trecho da Lógica, podemos ler:

$\mathrm{Na}$ medida em que ocorrências passadas têm sido analisadas o suficiente para que proporcionem a base de uma expectativa, esta última participa da natureza da inferência. Mas na medida em que têm servido de base para a predição ocorrências meramente temporais, a expectativa não constitui uma inferência em seu sentido lógico definido. Converte-se em tal inferência quando nos asseguramos de que certos modos constantes de operação natural são as razões pelas quais se podem usar como base da predição certas conjunções de condições circunstanciais (Dewey, 1960, p. 252).

Em suma, percebemos que, para Dewey, é preciso antes de tudo investigar as condições existentes, tendo-se em foco as conexões que guardam entre si. Estas, afirma o filósofo, são "geralmente de causa e efeito" (Dewey, 1960, p. 173). O passo seguinte se dá com a formulação destas conexões "em proposições conceituais abstratas generalizadas, em regras, princípios, leis" (Dewey, 1960, p. 173).

Dewey considera a linguagem um produto humano que envolve não apenas o fator oral e escrito, como também "os gestos, os ritos, cerimônias e monumentos, os produtos das belas artes e das artes industriais" (Dewey, 1960, p. 46). Uma máquina, por exemplo, é algo mais que um instrumento, sendo ainda um modo de linguagem. Aqueles que a conhecem sabem que algo nela lhes diz o que a máquina é capaz de executar, quais os efeitos que produz. Qualquer coisa que seja um instrumento, na opinião do autor, o é devido à linguagem:

Desde que ser um instrumento, ou ser utilizado enquanto meio para consequências, é ter e ser dotado de significado, a linguagem, sendo o instrumento dos instrumentos, é a fonte da qual emana toda significação. Pois as outras instrumentalidades e agências, as coisas comumente pensadas como utensílios, instrumentos e ferramentas, 
apenas podem originar-se e desenvolver-se em grupos sociais tornados possíveis pela linguagem (Dewey, 1958, p. 186).

Ademais, a importância da linguagem, necessária para a existência e a transmissão de atividades não puramente orgânicas e de suas consequências, reside no fato de ser ela, por um lado, um modo de comportamento estritamente biológico, já que surge em natural continuidade com atividades orgânicas prévias. Por outro, ela obriga o indivíduo a adotar o ponto de vista de outros; a inquirir desde um ponto de vista que não é estritamente pessoal, mas comum a indivíduos que participam de uma empresa conjunta. Para Dewey, a linguagem pode achar-se guiada por alguma existência física, mas primeiramente refere-se a outras pessoas com as quais se estabelece comunicação. Isso revela a capacidade que a linguagem tem de "fazer com que algo se torne comum" (Dewey, 1960, p. 46). As referências que a linguagem contém são, nesta medida, gerais e objetivas.

O filósofo entende que, embora a linguagem seja composta de "existências físicas" como, por exemplo, sons ou traços sobre um papel, estas existências físicas não funcionam como "coisas puramente físicas" quando vistas como meios de comunicação (Dewey, 1960, p. 46). Neste último caso, "operam em virtude de sua capacidade representativa ou sentido" (Dewey, 1960, p. 46). Em Como Pensamos (1910), estas existências físicas são entendidas de modo similar: "Os gestos, o sons, as formas escritas ou impressas, são existências estritamente físicas; mas seu valor inerente está propositadamente subordinado ao valor que adquirem como representantes de um sentido" (Dewey, 1959, p. 229). O exemplo que Dewey oferece, na Lógica, a respeito de um visitante recém-chegado a uma tribo selvagem, permite-nos compreender as duas citações, sobretudo do ponto de vista da linguística. O visitante queria saber qual era a palavra usada (de acordo com Dewey, o "símbolo") para a "mesa" diante dele. Bateu com o dedo na mesa e perguntou: "Que é isto?" Cinco garotos do lugar se aproximaram e o primeiro respondeu "dodela", o segundo "etanda", o terceiro "bokali", o quarto "elamba", e o quinto disse "meza". Espantado com a riqueza léxica do lugar, o visitante mais tarde veio a saber que o primeiro menino pensou que ele procurava saber a palavra para "golpear", o segundo achou que ele queria a palavra que designasse o "material" de que era feita a mesa, o terceiro pensou que a palavra buscada era a que designava "dureza", o quarto achou que se tratava da palavra para "aquilo que cobria" a mesa, e o quinto disse simplesmente "meza", ou seja, a mesa. Assim, cada palavra do dialeto local no exemplo acima não se reduz a um mero som, mas possui um sentido a ela atribuído pelos praticantes locais da língua em questão.

Podemos, neste ponto, observar que Dewey, em todas as suas explicações e exemplos, não perde de vista que a língua é uma totalidade ou estrutura com regras próprias de funcionamento. Ela também é tratada pelo filósofo como intrinsecamente relacionada ao uso de símbolos e de signos por um grupo de indivíduos emissores e receptores de mensagens ${ }^{1}$. Este uso, assim consolidado numa comunidade

\footnotetext{
1 O exemplo do dialeto da tribo selvagem sugere uma relação com uma das abordagens linguísticas de Saussure, a "sincrônica". Crystal (1977) nos explica que a linguística sincrônica "concebe a linguagem como totalidade viva, existente como 'estado', num determinado período de tempo (um état de langue, como diz Saussure). Podemos imaginar este estado como a acumulação de todas as atividades linguísticas que uma comunidade linguística (...) pratica, durante certo tempo" (Crystal, 1977, p. 193-4).
} 
linguística, é o que permite à linguagem desempenhar função essencial na condução da pesquisa controlada.

Os objetos naturais existentes são sinais de outros objetos e acontecimentos: "Nuvens representam chuva; pegadas, caça ou inimigo" (Dewey, 1959, p. 228). No caso específico da linguagem, uma existência física particular dotada de sentido não é algo apenas convencional. Dewey entende que a convenção ou consentimento comum, que coloca a linguagem à parte como um meio para registrar e comunicar sentido, relaciona-se, em verdade, com um acordo na ação; trata-se de "modos compartilhados de resposta ativa e de participação em suas consequências" (Dewey, 1960, p. 46). Tem-se, portanto, algo mais que uma convenção. O sentido possuído se estabelece por acordos entre diferentes pessoas envolvidas em atividades que fazem referência direta a consequências existenciais. Assim, um som ou uma grafia qualquer forma parte da linguagem sobretudo em virtude de sua força operativa. Ocorre-nos, neste ponto, mais um útil exemplo linguístico: suponhamos que um homem recebe um pacote com um bilhete em que está escrito "entregar para o chefe". As palavras ou símbolos "entregar" e "chefe" geram imediatamente uma determinada ação, e o fazem devido ao fato de o homem conhecer exatamente os sentidos atribuídos a estes símbolos. Assim, embora haja, sem dúvida, uma convenção com respeito ao sentido que as palavras destacadas possuem, o fato crucial é que as palavras estabelecem prontamente uma relação entre o que fazer com o pacote e a pessoa à qual o fazer é destinado. Isto, portanto, ilustra o sentido da declaração de Dewey de que "as palavras dizem o que querem dizer em conexão com atividades conjuntas que produzem uma consequência comum ou compartilhada" (Dewey, 1960, p. 53).

Dewey trata também do caso da conexão indireta entre a linguagem e as atividades ou ações efetivas. Nesta situação, a conexão com a ação se dá com possíveis modos de operação antes que com modos real e imediatamente requeridos: "a preparação para uma ação possível em situações que todavia não existem na realidade é condição e fator essencial de todo comportamento inteligente" (Dewey, 1960, p. 49). Nosso exemplo aqui é o de pessoas reunidas planejando o que farão mais tarde ou elaborando um modo alternativo de ação no caso de alguma ocorrência imprevista. O que se vê, em tal caso, é um acordo sobre operações solucionadoras que haverão de ser postas em prática. Em outros termos, é muito comum e necessário o ser humano deliberar e decidir antecipadamente qual o rumo de ação que deverá tomar a respeito de casos existenciais que exigem efetivamente uma solução. Notamos, assim, não o pensamento puro atuando na solução de uma dificuldade, mas um pensar que, mesmo não tendo ligação direta com fatos reais imediatamente presentes, trata da possibilidade de ocorrerem no futuro certas consequências práticas.

Dentre as peculiaridades da linguagem que Dewey aponta, merece especial destaque a de que nenhum som, traço ou qualquer elemento de comunicação pode ser visto como sendo meramente uma palavra ou uma parte da linguagem a ser considerada isoladamente. $\mathrm{E}$ isso, garante nosso autor, traz consequências importantes, já que qualquer palavra ou frase possui seu sentido unicamente como membro de um sistema de sentidos relacionados: "As palavras, em sua função representativa, são partes de um código amplo" (Dewey, 1960, p. 49). Assim sendo, e com base na distinção já apresentada entre sentidos conectados diretamente com a ação em situações atuais e sentidos relacionados com ações em possíveis situações futuras, Dewey passa a distinguir os códigos linguísticos como sistemas 
de dois tipos diferentes: um deles é "simplesmente a linguagem de uso comum" (Dewey, 1960, p. 50). Os sentidos nela existentes concordam não em virtude de sua relação recíproca, mas porque dizem respeito à mesma série de hábitos e expectativas do grupo. São interdependentes em razão de atividades, interesses, costumes e instituições de grupo. A ilustração que oferecemos é a de pessoas com vocação para a fé religiosa escutando alguém afirmar a frase: "A água deste rio que estão vendo é sagrada". Isto naturalmente levará as pessoas a tomar algum tipo de atitude condizente com seus hábitos de devoção, como talvez banhar-se no rio. Já "a linguagem científica, por sua vez, se acha submetida a uma prova que está acima deste critério" (Dewey, 1960, p. 50). Cada sentido que entra neste segundo modo de linguagem é determinado expressamente em sua relação com outros membros do sistema linguístico. Em todo discurso racional ou ordenado, este critério prevalece sobre aquele estabelecido em relação a hábitos culturais. Podemos nos referir ao caso do cientista que, em vez de utilizar a palavra "água", a substitui pela fórmula " $\mathrm{H}_{2} \mathrm{O}$ ". Ora, na linguagem científica, este termo é sinônimo de um certo estado de agregação, ou de certas afinidades que permitem à agua entrar em reações químicas com outros tipos de substâncias; é, pois, um termo que guarda relações, no sistema linguístico de que faz parte, com outras fórmulas ou termos. Assim, o cientista, na fase de seu trabalho em que apenas formula relações entre os termos, é capaz, por exemplo, de antecipar ou idealizar inúmeros estados ou ocorrências envolvendo reações químicas.

\section{IV: Os signos naturais e artificiais}

Pensamos ser necessário explicar, a esta altura, o modo preciso como Dewey entende alguns termos que ele mesmo utiliza, apenas para tornar mais clara sua concepção acerca da função e da utilidade da linguagem. Segundo Dewey, o uso dos signos naturais, ou do que ele mesmo chama de par signo-significado, é o que permite a inferência relativa a coisas imediatamente presentes e observadas - dizse que "isto" significa "aquilo", ou seja, de uma coisa se infere outra, como quando se diz que a "fumaça é um signo natural do fogo" (Dewey, 1960, p. 51). Em outras palavras, os signos naturais são as coisas existentes que, assim consideradas, indicam a existência de outras coisas, sendo estas outras coisas inferidas mais do que observadas diretamente. Dewey ainda distingue dos signos naturais os signos artificiais, ou o par símbolo-sentido, destacando que o uso deste novo par diz respeito, sobretudo, à implicação lógica, já que tais signos trazem o sentido das coisas, bem como suas relações recíprocas através das proposições. O símbolo, afirma Dewey, é aquilo que nomeia um objeto ou evento, "pois, do contrário, careceria de sentido e não seria um símbolo" (Dewey, 1960, p. 351). Ainda segundo o filósofo, cada símbolo "possui o sentido [...] daquilo que representa, ou seja, de seu referente" (Dewey, 1960, p. 366). Os sentidos, assim, são representações que operam independentemente da referência existencial e imediata. $\mathrm{Na}$ concepção de Dewey, portanto, temos, por um lado, os objetos naturais entendidos como sinais de outros objetos e acontecimentos. "Nuvens representam chuva; pegadas, caça ou inimigo; um rochedo que aflora, a presença de minerais no solo" (Dewey, 1959, p. 228). Por outro lado, os símbolos não representam meramente objetos, mas representam as relações entre eles tanto quanto as coisas que os objetos fazem. Os símbolos tornam possível o discurso ordenado ou o raciocínio; de fato, estes podem ser executados sem que se ache realmente presente qualquer existência a que se apliquem os símbolos. 
Não existiriam, garante Dewey, ideias e hipóteses de pesquisa se os símbolos e os sentidos não fossem distintos dos signos e dos significados. Sem dúvida, os símbolos também têm importância prática, mas o principal com respeito a eles é que introduzem na pesquisa uma dimensão puramente lógica dos atos humanos. Dewey utiliza o exemplo da nuvem. Uma nuvem negra vista por todos pode significar chuva iminente,

mas quando a palavra nuvem se conecta com outras pertencentes a uma constelação de símbolos, permite-nos relacionar o sentido de nuvem com assuntos tão diversos como diferenças de temperatura e de pressão, a rotação da terra, as leis do movimento e assim sucessivamente (Dewey, 1960, p. 53).

Da mesma maneira, em Como Pensamos encontramos as palavras não como sendo apenas os nomes ou os títulos das significações isoladas. As palavras formam também sentenças, em que as significações se organizam umas em relação às outras. Utilizemos agora a palavra "gato" como exemplo: esta pode, de acordo com a circunstância, referir-se ou aplicar-se a um gato aqui e agora. Mas do ponto de vista lógico, "gato" é um termo genérico que implica imediatamente outras noções, como a de animal, vertebrado, mamífero, quadrúpede, etc. Este é o caso, diz o filósofo, em que "exprimimos uma conexão lógica, um ato de classificação, de definição, que ultrapassa o elemento físico e entra no terreno lógico de gêneros e espécies, de coisas e atributos" (Dewey, 1959, p. 232).

Os dois pares de signos (naturais e artificiais) abrem caminho, portanto, para todo um mundo novo de percepção e conceituação. Na Lógica, o jogo das relações dos símbolos entre si é designado com o termo relação. Para o modo como os símbolos se relacionam com existências ou com os objetos da experiência é empregado o termo referência. Cabe esclarecer que a referência, para Dewey, é o que nos remete "a um singular ou isto" (Dewey, 1960, p. 354). Quanto a este ponto, comentaríamos que ela diz sempre respeito à existência observada de um objeto natural (ou uma coisa) neste lugar e tempo determinados. Já para as relações das coisas mesmas entre si o termo empregado é conexão - sendo esta identificada principalmente com a relação de causa e efeito encontrada entre os objetos, como já vimos. Segundo Dewey, estes "jogos" ou relações ocasionam comportamentos humanos cada vez mais requintados e complexos. Aqui, recordaríamos que estes procedimentos requintados podem ser identificados não apenas com a inferência, definida pela relação signo-significado, mas também com a operação lógica de implicação, definida pela relação que se estabelece entre os símbolos-sentidos, e assim por diante.

Dewey tenta explicar estas diferentes relações tomando em consideração as proposições da física. Estas, enquanto proposições, formam um sistema de símbolos-sentidos relacionados entre si de tal forma que este modo de relação pode ser cada vez mais enriquecido. Enquanto proposições próprias da física, referem-se a existências reais. Já a prova ou confirmação destas aplicações se dá nas conexões que as coisas mesmas mantêm entre si na existência. O filósofo, por outro lado, não nos dá qualquer ilustração a respeito, o que nos leva a considerar por um instante a proposição tão bem conhecida da física em que se afirma que "a propriedade do fogo que produz a evaporação dos líquidos é o calor". Ora, a simples 
afirmação traz apenas relações de símbolos-sentidos entre si (como a do símbolo "calor" com o símbolo "evaporação"). Sabemos, no entanto, que esta proposição refere-se a existências reais (ao fogo que acendemos no fogão e à água que retiramos da torneira). E se realmente fazemos a experiência do aquecimento da água, vemos que de fato ela evapora após ser submetida à ação das chamas do fogão, ou seja, vemos acontecer a conexão que as coisas mesmas guardam entre si na experiência.

Comentando a teoria da linguagem de Dewey, Piatt (1939) afirma encontrar, no que respeita ao par "signo-significado", não apenas o "significado", mas ainda outra relação que ele chama de "significação". O modo como Dewey considera este par parece ser simplório, na visão do comentador. Para Piatt, não se tem, neste par, um simples significado de um objeto (como quando nuvem simplesmente significa chuva); tem-se, além disso, uma significação considerada mais complexa, e que ele chama de "instrumental". Explica Piatt que,

no caso simples, uma coisa sugere outra, sem instigar reflexão ou pesquisa. No mais complexo, a inferência de uma coisa a outra é tornada explícita pela pesquisa. Paramos para analisar a primeira coisa para determinar 0 que há sobre ela que garante 0 aparecimento da outra. Queremos saber se a nuvem realmente significa chuva, se é mesmo uma nuvem, etc. Nesta pesquisa, passamos de um objeto a outro por meio de símbolos ou ideias. Mas embora estes símbolos-sentido sejam importantes, são intermediários - pensamos "com" eles e não "sobre" eles (Piatt, 1939, p. 123).

Max Black (1962) também apresenta algumas críticas relevantes à teoria da linguagem de Dewey. O comentador pergunta, por exemplo, como pode ser explicada, com base em princípios behavioristas, a resposta inteligente a signos (isto é, a signos com certos significados). Ele mesmo declara não ter encontrado a este respeito qualquer discussão satisfatoriamente realizada por Dewey. Esclarece Black:

Suponha que um organismo, que inicialmente produz algum padrão de resposta a um estímulo de tipo $A$, é repetidamente exposto a um estímulo $A$ acompanhado de outro estímulo de tipo $B$, e finalmente condicionado a responder a um estímulo de tipo B sozinho. Quando isto ocorre, a resposta ao estímulo $B$, chamada $R_{B}$, será sempre diferente da resposta original ao estímulo $A$, chamada $R_{A}$ (Black, 1962, p. 511).

Black, referindo-se ao cão de Pavlov, afirma ainda que "o cão é condicionado a salivar ao som de um sino, mas ele não tenta comê-lo" (Black, 1962, p. 511). Defende Black, portanto, que uma análise behaviorista do comportamento por meio do signo deve especificar a relação entre $R_{B}$ e $R_{A}$, em virtude da qual a primeira resposta contará como um caso de tratar B como signo de $A$. Mas, segundo 0 comentador, Dewey fica-nos devendo uma análise desta natureza. 
Já com respeito ao uso que Dewey faz do termo "sentido", o mesmo comentador elenca algumas definições encontradas nos escritos de Dewey para este termo, o conjunto das quais, segundo ele, apresenta dificuldades. Em uma das citações, temos que "um sentido é um método de ação" (Dewey apud Black, 1962, p. 517). Em outra ainda, uma "ideia ou sentido conceitual" é uma "atitude" (Dewey apud Black, 1962, p. 517). Ideias ou sentidos são também "planos e desígnios antecipatórios" (Dewey apud Black, 1962, p. 517). Estas e outras fórmulas de Dewey possuem - constata Black - apenas uma vaga referência à ação verificacional, e o comentador tem ainda a impressão de que Dewey usa estas várias formulações como se elas diferissem apenas quanto a desprezíveis gradações de significado. Adverte Black, no entanto, que, na construção de tais formulações, "as diferenças não são desprezíveis. Se estamos falando com considerável grau de precisão, devemos escolher entre regras [...], métodos, [...] atitudes, planos e desígnios, os quais Dewey mistura" (Black, 1962, p. 517). Conclui Black que, caso não se faça esta escolha, o que resulta é uma ideia obscura de "sentido", a qual teria apenas "alguma coisa a ver com consequências futuras, com operações, planos e assim por diante" (Black, 1962, p. 517).

Outra dificuldade encontrada por Black diz respeito à tentativa de Dewey de rejeitar a tendência em identificar o sentido com qualquer evento psíquico ou essência transcendental. Para Black, Dewey parece conceber o sentido como um "correlativo não verbal" de um símbolo (Black, 1962, p. 519). Em outros termos, Dewey pareceria aceitar o princípio de que o sentido distintivo de um dado símbolo pode ser designado de forma independente. Mas como entender exatamente este "correlativo não verbal" de que fala Black? Explica o comentador que uma questão da forma: "qual é o sentido de S?" pode ser respondida com uma afirmação da forma "o sentido de S é M", em que a letra "M" é substituída pela designação de um sentido. Assim, diz Black que, se Dewey afirma que o sentido de "doce" é um certo plano de ação, ele parece se referir a algo (ou seja, o plano de ação) que existe independentemente do símbolo, do qual, no entanto, é o sentido. Ora, isto pode ser chamado, segundo Black, de o "dogma do sentido essencial" (Black, 1962, p. 519). Com efeito, em uma passagem da Lógica destacada por Black, Dewey diz que não é possível algo como "uma correspondência unívoca dos nomes com objetos existenciais" (Dewey, 1960, p. 53). Pois ele teria feito melhor, defende Black, negando a correspondência unívoca com quaisquer tipos de objetos. Dewey tenta evitar qualquer atitude que possa ser interpretada como o "hipostaziar da essência", mas o fato é que acaba por "sucumbir a uma mais sutil variação deste mesmo erro" (Black, 1962, p. 519).

\section{Conclusão}

Para concluir, reconduzamo-nos agora à questão apresentada no início do presente artigo: a transformação das atividades animais em conduta inteligente, a qual possui propriedades que, uma vez formuladas, resultam de natureza lógica. $\mathrm{O}$ intuito é observar, na Lógica, quais os efeitos que esta transformação tem sobre o comportamento associado humano. $\mathrm{Na}$ visão do filósofo, o comportamento associado caracteriza não só plantas e animais, "como também os elétrons, átomos e moléculas; e podemos presumir que a tudo o que existe na natureza" (Dewey, 1960 , p. 56). Diríamos que o comportamento associado de que fala Dewey significa que nenhum ato ocorre independentemente do que quer que exista ao redor do ser que executa o ato. Mesmo no nível dos corpos físicos mais elementares, como os 
átomos, as leis físico-químicas, que explicam a ocorrência de ligações e combinações, mostram que todos os tipos de objetos naturais existem sempre em relação uns com os outros. Basta considerarmos ainda que a fotossíntese de uma planta, por exemplo, não é um fenômeno simplesmente isolado. Ao invés disso, ela se dá em associação com elementos ambientais, já que a planta absorve gás carbônico e libera oxigênio no meio, afetando a atmosfera. Especialmente na conduta humana associada, a ação do homem nunca é um acontecimento isolado ou independente, já que afeta não só o ambiente como os outros homens que com ele compartilham de um espaço físico, de uma determinada opinião ou crença, etc. No nível humano, Dewey ainda entende que, embora a associação não seja produto da linguagem, esta última, quando se dá como emergência natural a partir de formas prévias de atividade animal, repercute transformando de forma tal os modos anteriores de comportamento associado, que confere uma nova dimensão à experiência. Aqui, diríamos que a cultura transforma radicalmente, entre outras coisas, o modo de o homem relacionar-se com seus iguais, o que the proporciona novas experiências. O homem pode, então, conversar, alegrar-se cantando com outros, planejar melhor e com mais cuidado ações a serem executadas coletivamente, etc. Dentre as consequências relevantes, contidas na Lógica, do surgimento da conduta inteligente e da linguagem sobre a conduta humana associada, destacaremos as que seguem:

As atividades animais como as de comer e beber, por exemplo, adquirem novas propriedades: comer se converte em festa e celebração de grupo; procurar alimento se transforma na arte da agricultura, etc.

Esclarece Dewey que, independentemente da existência de símbolossentidos, quaisquer resultados da experiência anterior se conservam unicamente por meio de modificações estritamente orgânicas. Quando se dão tais modificações, elas tendem a fixar-se de tal modo que retardam ou mesmo impedem ulteriores modificações que se mostram necessárias. A existência de símbolos, por sua vez, torna possível a recordação e a expectativa deliberadas, e possibilita novas combinações de elementos escolhidos das experiências que possuem dimensão intelectual.

Outra consequência extraída por Dewey é que as atividades puramente biológicas desembocam em ações exteriores cujas consequências são irreversíveis. Quando a atividade e suas consequências podem seguir-se mediante representação com termos simbólicos, não temos tal resultado permanente. Se a representação da consequência final é de qualidade desagradável, podemos omitir a ação exterior ou planejar de novo o modo de atuar, de modo a evitar o resultado indesejável.

Finalmente, o uso dos símbolos-sentidos como instrumentos para a deliberação e o planejamento, e para a consequente transformação das circunstâncias do meio, é, no mínimo, uma forma rudimentar de se buscar soluções de problemas com o auxílio do raciocínio. Este, por sua vez, quando se transforma em hábito, tende a se desenvolver indefinidamente: "quando isto ocorre, as condições lógicas implícitas se tornam explícitas e nasce algum gênero de teoria lógica" (Dewey, 1960, p. 57).

Para Dewey, em suma, a linguagem, como tudo o que envolve a cultura humana, é desenvolvida em continuidade com atividades puramente biológicas e não por meio de um salto brusco ou de um ato descontínuo com respeito a estas mesmas atividades. Segundo o autor, isto possibilita ao ser humano dispor de 
condições mais eficientes de adaptação. Abre-se, assim, o caminho para uma maior eficiência na comunicação e entendimento mútuos, o que sugere a ideia de que a pesquisa humana voltada para questões da vida comum mantém uma relação de continuidade com a pesquisa propriamente científica. Diríamos que, para Dewey, não há qualquer tipo de procedimento humano comumente chamado de intelectual ou lógico que assim o seja exclusivamente. Qualquer atividade que exija habilidades de raciocínio lógico, como o exige a atividade científica transformadora do meio, pode ser descrita em termos de uma atividade orgânica dirigida por símbolossentidos, os quais, por sua vez, devem ser aceitos e compartilhados por uma comunidade de pessoas.

\section{Referências}

BLACK, M. Dewey's Philosophy of Language. The Journal of Philosophy, v.59, n.19, 1962.

DEWEY, J. Reconstruction in Philosophy. Mentor Book, The New American Library, 1950.

La Búsqueda de la Certeza: un estudio de la relación entre el conocimiento y la acción. Buenos Aires, Fondo de Cultura Económica, 1952.

. Experience and Nature. New York: Dover Publications, 1958.

. Como Pensamos. São Paulo: Companhia Editora Nacional, 1959.

Logic: The Theory of Inquiry. New York: Holt, Rinehart and Winston, 1960.

Cultural, 1974.

Textos Selecionados. Col. Os Pensadores, v. 40. São Paulo: Abril

. The Development of American Pragmatism. The Essential Dewey, vol. I: Pragmatism, Education, Democracy. Bloomington \& Indianapolis: Indiana University Press, 1998.

2, 2007.

. O desenvolvimento do pragmatismo americano. Scientiae Studia, v. 5, n.

CRYSTAL, D. A linguística. Lisboa: Publicações Dom Quixote, 1977.

PIATT, DONALD A. Dewey's Logical Theory. The Philosophy of John Dewey (Library of Living Philosophers), Evanston and Chicago: Northwestern University, 1939. 